\title{
Equilibrium and Kinetic Study on the Biosorption of Trypan Blue from Aqueous Solutions using Avocado Seed Powder
}

\author{
Tamer T. El-Idreesy ${ }^{1,2, * \mathbb{D}}$, Omar Khoshala ${ }^{2}$, Amin Firouzi ${ }^{3}$, Hany A. Elazab ${ }^{4,5, * \mathbb{C}}$ \\ 1 Department of Chemistry, Faculty of Science, Cairo University, Giza 12613, Egypt.; e-mail: tamer@cu.edu.eg \\ (T.T.E.-I.); \\ 2 Department of Chemistry, School of Sciences and Engineering, The American University in Cairo, New Cairo 11835, \\ Egypt.; e-mail: okhshala@auc.edu.eg (O.K.); \\ 3 Department of Biomedical Engineering, University of Houston, Houston, TX, 77204, USA \\ 4 Department of Chemical Engineering, Faculty of Engineering, The British University in Egypt, El-Shorouk City, Cairo, \\ Egypt \\ 5 Nanotechnology Research Centre (NTRC), the British University in Egypt (BUE), El-Sherouk City, Suez Desert Road, \\ Cairo, 11837, Egypt.; e-mail: elazabha@vcu.edu (H.A.E.); \\ * Correspondence: elazabha@vcu.edu (H.A.E.); tamer@cu.edu.eg (T.T.E.-I.);
}

Scopus Author ID 57197864132 (H.A.E.)

Scopus Author ID 6507120225 (T.T.E.-I.)

Received: 16.09.2020; Revised: 10.11.2020; Accepted: 12.11.2020; Published: 16.11.2020

\begin{abstract}
This research aims to investigate the removal of trypan blue dye from aqueous solutions by employing ground avocado seeds powder, a low-cost biowaste adsorbent (biosorbent), under various experimental conditions. The effect of contact time, initial dye concentration, and adsorbent dose on dye removal were studied. The experimental kinetic data were fitted to pseudo-first-order and pseudosecond-order kinetic models. Results imply that adsorption of trypan blue on the avocado seed adsorbent nicely followed the pseudo-second-order kinetic model. Equilibrium isotherms were analyzed by Langmuir and Freundlich isotherms, where Langmuir isotherm described the isotherm data with a highcorrelation coefficient $\left(\mathrm{R}^{2}=0.9948\right)$ closer to unity, and maximum adsorption capacity was found to be $19.3 \mathrm{mg} \mathrm{g}^{-1}$. The present study results substantiate that ground avocado seeds are a promising adsorbent for the removal of the dye trypan blue from industrial wastewater.
\end{abstract}

Keywords: dye removal; biosorbent; wastewater treatment; pollution; kinetic models.

(C) 2020 by the authors. This article is an open-access article distributed under the terms and conditions of the Creative Commons Attribution (CC BY) license (https://creativecommons.org/licenses/by/4.0/).

\section{Introduction}

Water is a vital and essential compound for life on earth [1-7]. The major sources of water pollution include wastewater discharge from industries and agricultural activities. The presence of contaminants, including heavy metals, dyes, and microorganisms, even in very small amounts, still proves to be very dangerous to not only human health but to aquatic systems and the environment alike [8-14].

Several remediation approaches have been adopted to remove such pollutants from wastewater. Those proposed techniques include precipitation, incineration, flocculation, coagulation, ion exchange, reverse osmosis, membrane filtration, electrochemistry, photoelectrochemistry, among many others. Some downsides of said methods are the low removal efficiency, high production and maintenance costs, and the generation of potentially toxic by-products and introducing this to the environment [15-22]. 
Adsorption by solid adsorbents is considered an effective method for the treatment and removal of several contaminants in wastewater treatment. Adsorption has advantages over the other methods because of simple design, ease of operation, low cost, and high performance. Nowadays, adsorption processes are widely used to treat industrial wastewater from both organic and inorganic pollutants. Materials widely available such as agricultural and industrial wastes can be used as low-cost adsorbents. Additionally, activated carbon can be produced from these waste materials upon some chemical and thermal treatment and be utilized as an adsorbent for water and wastewater treatment. [23-28] Thus, this study aims to examine the efficacy of avocado seeds, a common biowaste, in adsorbing dyes present in industrial wastewater [29-31].

Biosorption is a physiochemical process by which certain biomass passively concentrates and binds contaminants onto its cellular structure. In the past, the term biosorption was used to describe metal removal by microorganisms. The terms biosorption and bioaccumulation are used interchangeably in the literature; however, a distinction has to be made. Bioaccumulation is based on the use of living cells, while biosorption is based on dead biomass use [32-36]. The biosorption of toxic metals, dyes, and other pollutants is affected by several factors, such as the solution $\mathrm{pH}$, temperature, contaminant concentration, time, and ionic strength. Among all these factors, $\mathrm{pH}$ is considered one of the most if not the most important key factor of the biosorption process [37-44]. The $\mathrm{pH}$ affects the solution chemistry of metals and the functional groups' activity present in the biosorbent. As the $\mathrm{pH}$ decreases, the competition among proton and metal ions in solution for functional groups present on the biosorbent surface increases, reducing the biosorption capacity. Nevertheless, at high $\mathrm{pH}$ values, the metal uptake is affected by the insoluble metal compound's formation. [45-48] Before going in further, some terminology regarding adsorption processes will need to be addressed. Adsorption is when atoms, ions, or molecules from a gas, liquid, or dissolved solid adhere to a surface. The adsorbent is a substance that is usually porous with a high surface area that can adsorb substances onto its surface with the help of intermolecular forces, while the adsorbate is a substance that gets adsorbed on a surface of another substance, which is the adsorbent in this case. The amount of dye adsorbed, $\mathrm{q}_{\mathrm{e}}$, is given by equation 1 , where $\mathrm{C}_{0}$ is the initial dye concentration, $\mathrm{C}_{\mathrm{e}}$ is the final dye concentration, $\mathrm{V}$ is the solution volume, and $\mathrm{W}$ is the added weight adsorbent [47-50].

Accordingly, when a solution containing pollutants (absorbable solute) comes into contact with a solid with a highly porous surface structure (adsorbent), intermolecular forces of attraction cause some of the pollutants in the solution to get deposited at the solid surface, and that's the main principle behind using adsorption for wastewater treatment [51-54].

\section{Materials and Methods}

\subsection{Materials.}

Chemicals were used as received without any modification or further steps of purification. Avocado seeds were the natural biosorbent choice for this study. Trypan Blue $\left(\mathrm{C}_{34} \mathrm{H}_{24} \mathrm{~N}_{6} \mathrm{Na}_{4} \mathrm{O}_{14} \mathrm{~S}_{4}\right)$ was the dye used to test out the adsorbent's effectiveness, as shown in figure 1. Usually, more popular dyes like methylene blue or crystal violet are used for such studies, but that does not undermine the importance of studying the effectiveness of a natural biosorbent on adsorbing the trypan blue dye. Trypan Blue is an azo acid dye commonly used as a stain to differentiate amongst viable and non-viable cells. This azo dye turns dead cells 
blue while leaving viable cells unstained. It's also used for directly dyeing cotton textiles. However, it's not as popular in the textile industry as the aforementioned dyes above.

Furthermore, it is a known animal carcinogen and an experimental teratogen. Its introduction to the environment in the form of waste from the textile industry can prove to be a serious threat to the environment and animals and humans alike. The dye is readily soluble in water and was found to have a UV maximum absorption range of 584-617 nm.

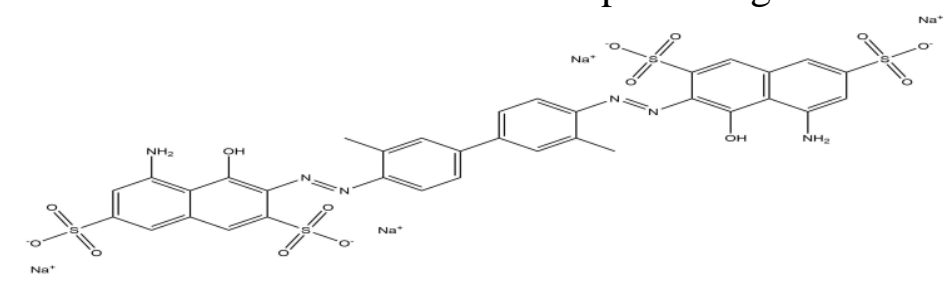

Figure 1. Structure of the trypan blue dye.

\subsection{Preparation of the adsorbent and dye stock solutions.}

In the typical synthetic procedure, Avocados seeds were extracted from locally bought avocados. They were then thoroughly washed with distilled water, dried at $80{ }^{\circ} \mathrm{C}$ in an oven for $24 \mathrm{~h}$, and then cut and ground to a fine powder. During the thermal treatment, a loss of biomass was produced. The percentage of loss was determined using equation 10 shown below, where, $\mathrm{m}_{\mathrm{i}}$ and $\mathrm{m}_{\mathrm{f}}(\mathrm{g})$ are the initial and final biomass, respectively.

The Trypan Blue Dye purchased from Serva chemicals of $99.9 \%$ purity was available in powder form, so a stock solution was made by dissolving a certain amount of the dye into distilled water to obtain a stock solution with a final concentration of $1 \times 10^{-3} \mathrm{M}$ using equation 11 , where wt is the weight of the dye needed in grams, $\mathrm{C}$ is the final desired concentration in $\mathrm{M}, \mathrm{V}$ is the volume of the solution in $\mathrm{ml}, \mathrm{Mr}$ is the molecular weight of the dye, and divide by a thousand to convert milliliter to liter. Accordingly, the stock solution was diluted even further to obtain six trypan blue solutions in various concentrations, namely, $1 \times 10^{-5} \mathrm{M}, 2 \times 10^{-5} \mathrm{M}, 4 \times 10^{-}$ ${ }^{5} \mathrm{M}, 6 \times 10^{-5} \mathrm{M}$, and $8 \times 10^{-5} \mathrm{M}$.

\subsection{The adsorption experiments.}

For all the experiments, $250 \mathrm{ml}$ conical flasks were used along with hot plate stirrers and stirring bars of the same size. Stuart Magnetic stirrer with heating analog US152 was used for both the heating and stirring at a fixed stirring rate (scale 3 on the device). Additionally, a fixed volume of $25 \mathrm{ml}$ of the dye solution was used for all the tests. The adsorbent dose and time sometimes varied depending on the test. The effect of time, adsorbent dose, and initial dye concentration on the dye's percentage removal were explored thoroughly in this study.

After the tests are carried out, a UV reading at $\lambda_{\max }=580 \mathrm{~nm}$ is taken to determine the final absorption value. Hence, the dye's final concentration remaining in the solution is determined using the best fit line equation of the calibration curve. Finally, equation 13 is used to calculate the $\%$ adsorption or removal of the dye in the solution $[1,11,24,42]$.

\section{Results and Discussion}

\subsection{Effect of initial dye concentration.}

Table 1 discuss the influence of using different concentrations on the absorbance. The effect of initial dye concentration was the first effect studied in this work. A series of five Trypan Blue solutions with $1 \times 10^{-5} \mathrm{M}, 2 \times 10^{-5} \mathrm{M}, 4 \times 10^{-5} \mathrm{M}, 6 \times 10^{-5} \mathrm{M}$, and $8 \times 10^{-5}$ initial dye concentrations were used in this study. The calibration curve is shown in figure 3. 
Table 1. The impact of using different concentrations on absorbance.

\begin{tabular}{c|c} 
Concentration $(\mathbf{m o l} / \mathbf{L})\left(\mathbf{1 x 1 0}^{-5}\right)$ & Absorbance \\
\hline $\mathbf{1}$ & 0.274 \\
\hline $\mathbf{2}$ & 0.59 \\
\hline $\mathbf{4}$ & 1.165 \\
\hline $\mathbf{6}$ & 1.694 \\
\hline $\mathbf{8}$ & 1.965
\end{tabular}

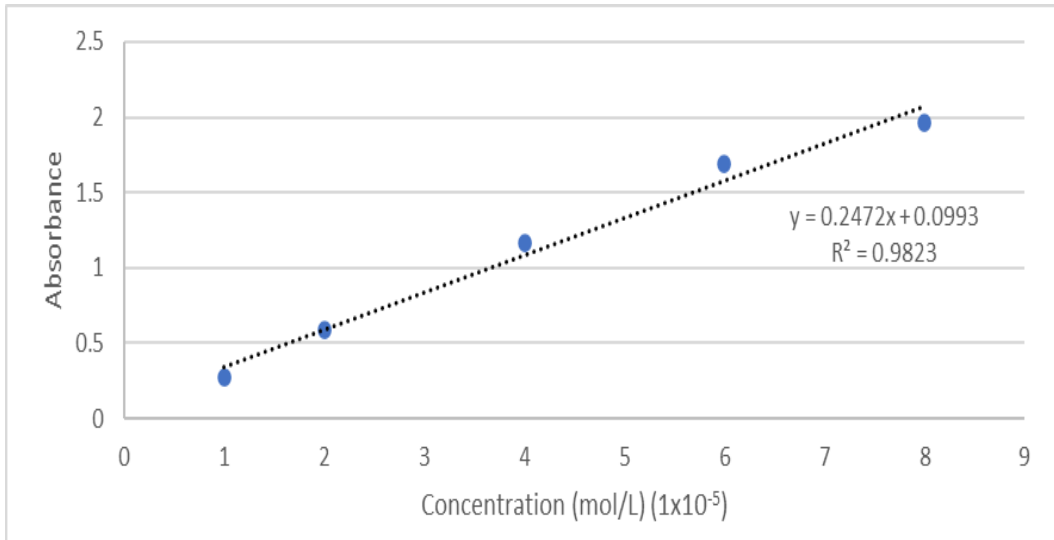

Figure 3. Calibration curve.

Table 2. The effect of initial dye concentration.

\begin{tabular}{c|c|c|c}
$\begin{array}{c}\mathbf{C}_{\mathbf{0}}(\mathbf{m o l} / \mathbf{L}) \\
(\mathbf{1 x 1 0})\end{array}$ & Absorbance & $\mathbf{C}_{\mathbf{e}}(\mathbf{m o l} / \mathbf{L})$ & $\begin{array}{c}\mathbf{\%} \\
\text { Removal }\end{array}$ \\
\hline $\mathbf{1}$ & 0.061 & $1.55 \mathrm{E}-06$ & $84.5 \%$ \\
\hline $\mathbf{2}$ & 0.12 & $8.37 \mathrm{E}-07$ & $95.8 \%$ \\
\hline $\mathbf{4}$ & 0.215 & $4.68 \mathrm{E}-06$ & $88.3 \%$ \\
\hline $\mathbf{6}$ & 0.293 & $7.84 \mathrm{E}-06$ & $86.9 \%$ \\
\hline $\mathbf{8}$ & 0.736 & $2.57 \mathrm{E}-05$ & $67.8 \%$
\end{tabular}

As discussed before, table 2 shows the effect of initial dye concentration was investigated through a series of five Trypan Blue solutions with $1 \times 10^{-5} \mathrm{M}, 2 \times 10^{-5} \mathrm{M}, 4 \times 10^{-5} \mathrm{M}$, $6 \times 10^{-5} \mathrm{M}$, and $8 \times 10^{-5}$ initial dye concentrations used in this study.

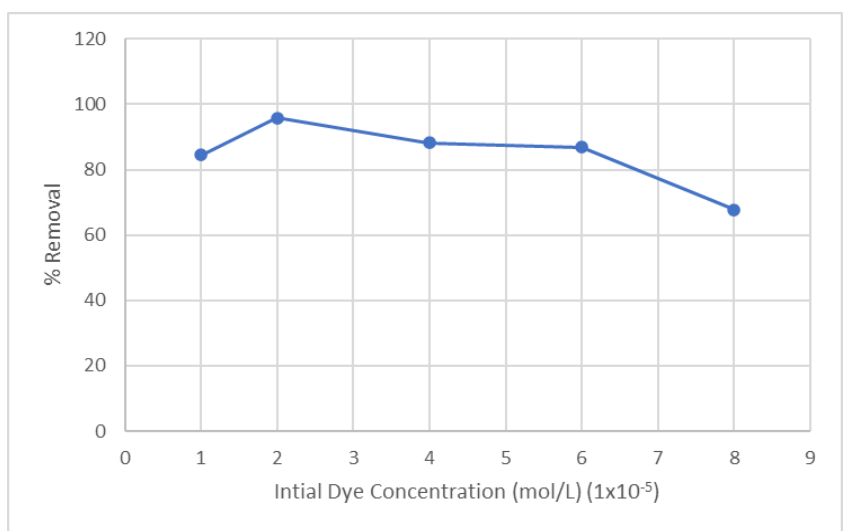

Figure 4. Effect of initial dye concentration.

It seems that the investigated series of the selected five Trypan Blue solutions with $1 \times 10^{-5} \mathrm{M}, 2 \times 10^{-5} \mathrm{M}, 4 \times 10^{-5} \mathrm{M}, 6 \times 10^{-5} \mathrm{M}$, and $8 \times 10^{-5} \mathrm{M}$ initial dye concentrations used in this study have different removal percentage as $2 \times 10^{-5} \mathrm{M}$ is the best and efficient concentration in removal percentage, however, increasing the concentration could not enhance the removal efficiency as it keeps decreasing until the minimum removal percentage was recorder for $8 \times 10^{-}$ ${ }^{5} \mathrm{M}$ as shown in figure 4. 


\subsection{Effect of contact time.}

Like temperature, $\mathrm{pH}$, and the bisosorbent dose, all other variables were kept constant in this study. The solutions were all stirred for ten minutes, filtered, and then their UV absorptions were measured after, as shown in table 3 . It appears that $2 \times 10^{-5} \mathrm{M}$ is the optimum initial dye concentration capable of removing $95.8 \%$ of the trypan blue dye from the prepared aqueous solution.

Beyond this point, it appears that saturation was achieved, and an increase in the dye concentration would lead the equilibrium to shift back to the left and promote desorption instead of adsorption.

Table 3. The effect of contact time.

\begin{tabular}{c|c|c|c} 
Time (min) & Absorbance & Ce(mol/L) & \% Removal \\
\hline $\mathbf{1 0}$ & 0.594 & $2.13 \mathrm{E}-05$ & $65.8 \%$ \\
\hline $\mathbf{2 0}$ & 0.584 & $1.96 \mathrm{E}-05$ & $67.3 \%$ \\
\hline $\mathbf{3 0}$ & 0.428 & $1.33 \mathrm{E}-05$ & $77.8 \%$ \\
\hline $\mathbf{4 0}$ & 0.389 & $1.17 \mathrm{E}-05$ & $80.5 \%$
\end{tabular}

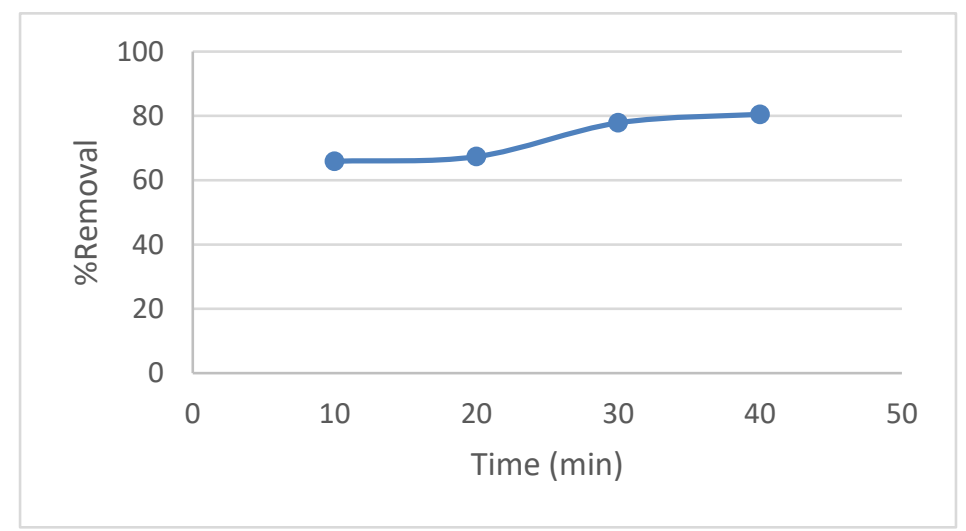

Figure 5. Effect of contact time.

Once the initial dye concentration was examined, the contact time was the second effect to be studied. Studying the effect of contact time is of great importance because it could lead to greater efficiency if, for instance, 30 minutes was the time need to get optimum results, then leaving it for more time would be ineffective and might lead to desorption. All the variables like temperature, biosorbent dose, and dye concentration were fixed at $6 \times 10^{-5} \mathrm{M}$, and only contact time was varied from 10 to 60 minutes. As seen in figure 5, starting from the 30-minute mark, the plot starts to plateau. Hence, it can be concluded that this is an experimental qe value, and going beyond this point wouldn't be productive since the percent removal wouldn't vary by much at all since the adsorbent is most likely fully saturated at this point.

\subsection{Effect of biosorbent dose.}

Table 4 reveals that the dose of the biosorbent used is one of the most important variables studied in this work since it determines the capacity of the biosorbent.

Table 4. The effect of biosorbent dose.

\begin{tabular}{l|l|l|l}
$\mathbf{M a s s}(\mathbf{g})$ & Absorbance & $\mathbf{C}_{\mathrm{e}}(\mathbf{m o l} / \mathbf{L})$ & \% Removal \\
\hline $\mathbf{0 . 0 5}$ & 1.321 & $4.94 \mathrm{E}-05$ & $17.6 \%$ \\
\hline $\mathbf{0 . 1}$ & 0.994 & $3.62 \mathrm{E}-05$ & $39.7 \%$ \\
\hline $\mathbf{0 . 2}$ & 0.693 & $2.40 \mathrm{E}-05$ & $59.9 \%$ \\
\hline $\mathbf{0 . 3}$ & 0.334 & $9.49 \mathrm{E}-06$ & $84.2 \%$ \\
\hline $\mathbf{0 . 4}$ & 0.55 & $1.82 \mathrm{E}-05$ & $69.6 \%$
\end{tabular}




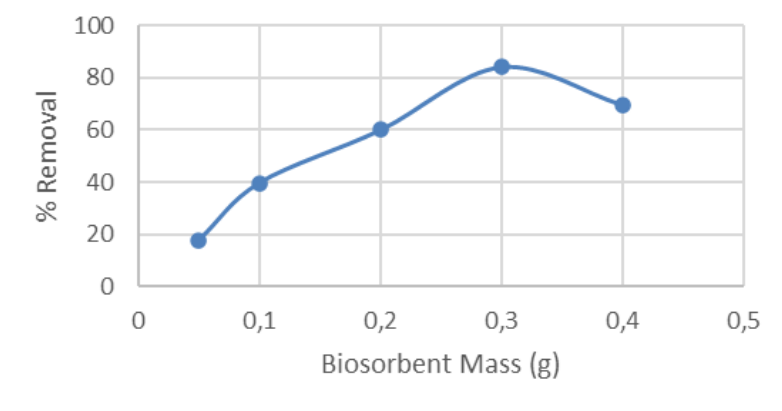

Figure 6. Effect of biosorbent dose.

The amount of avocado seed powder (biosorbent) was changed from 0.05 to 0.4 grams in $25 \mathrm{ml}$ of dye solution of the same concentration of $6 \times 10^{-5} \mathrm{M}$. All the other variables such as the contact time, $\mathrm{pH}$, and temperature were kept constant. Once again, the solutions were all stirred for ten minutes, filtered, and then their UV absorptions were measured after. Figure 6 shows that as the dose increases from 0.05 to 0.3 grams, the removal percentage increased from $17.6 \%$ to $84.2 \%$, but then there's a dip in the percent removal with the test run with 0.4 grams of the biosorbent, and this might be due to the saturation effect of the dye-binding sites leading to aggregation, for instance. From the data shown in the table, it appears that $0.3 \mathrm{~g}$ is the optimum biosorbent dose.

\subsection{Adsorption isotherms.}

In order to use the equations of the adsorption isotherms, the concentrations need to be in $\mathrm{mg} / \mathrm{L}$. The equation below was used to change the concentrations from molarity to $\mathrm{mg} / \mathrm{L}$, and the results are shown below in table 5. To quantitatively compare the two models' accuracy, the correlation coefficients were calculated where the model having a higher correlation coefficient would fit the data best.

Concentration $\left(\frac{m g}{L}\right)=$ Concentration $(M) \times$ Molecular Weight of the Dye $\times 100$

Table 5. Concentration conversion from $\mathrm{mol} / \mathrm{L}$ to $\mathrm{mg} / \mathrm{L}$.

\begin{tabular}{c|c}
$\mathbf{C}_{\mathbf{0}}(\mathbf{M})\left(\mathbf{1 x 1 0} \mathbf{1 0}^{-5}\right)$ & $\mathbf{C}_{\mathbf{0}}(\mathbf{m g} / \mathbf{L})$ \\
\hline $\mathbf{1}$ & 9.608 \\
\hline $\mathbf{4}$ & 38.432 \\
\hline $\mathbf{6}$ & 57.648
\end{tabular}

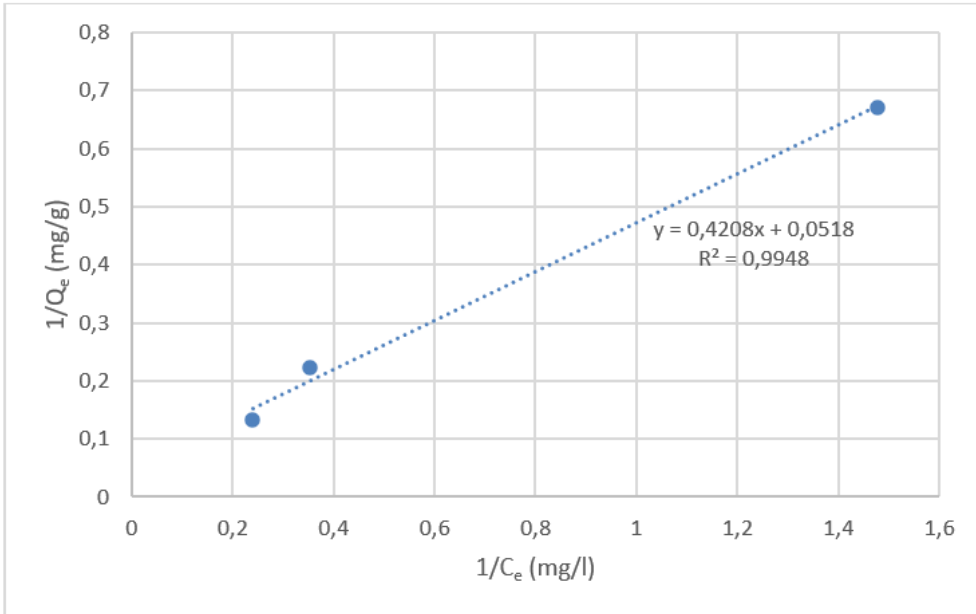

Figure 7. Langmuir isotherm. 


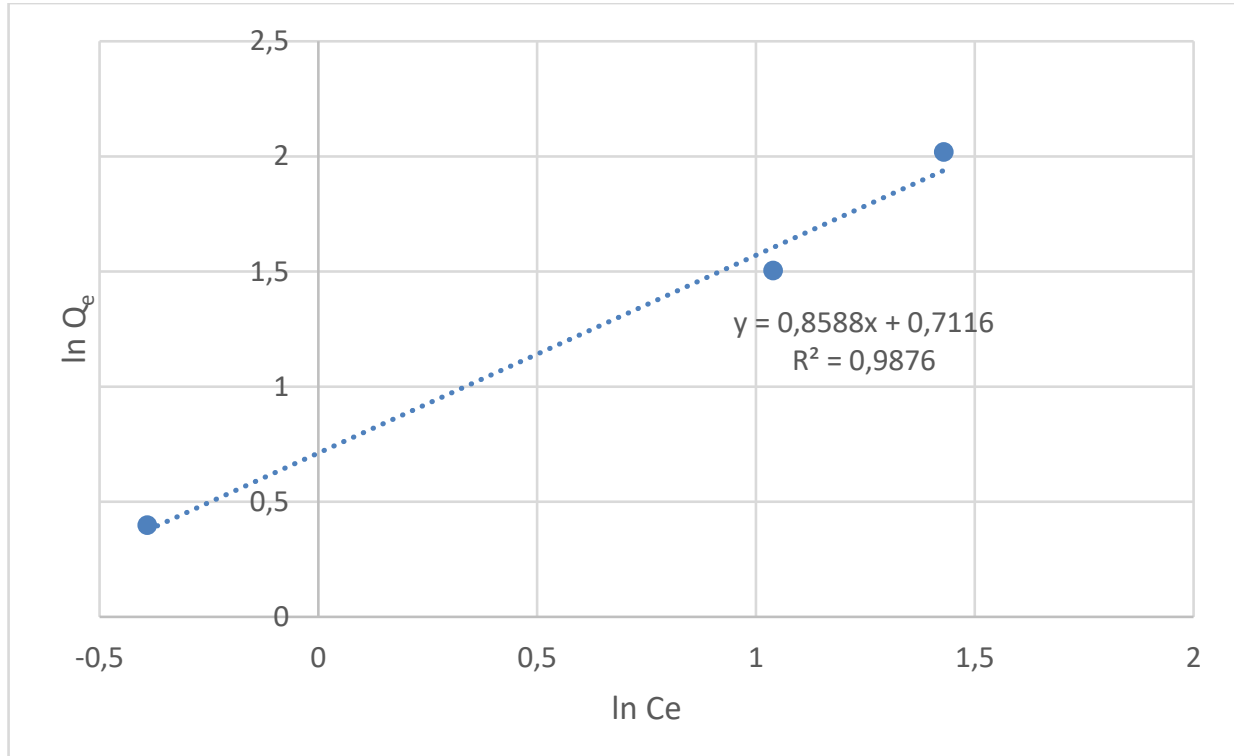

Figure 8. Freundlich isotherm.

The higher correlation coefficient $\left(\mathrm{R}^{2}=0.9948\right)$, as shown in figure 7 indicates that the Langmuir isotherm model describes trypan blue's adsorption onto the avocado seed powder best. Moreover, the separation factor, $\mathrm{R}_{\mathrm{L}}$ is 0.464 , lying in the middle of zero and one, which is matching the typical adsorption process according to the Langmuir model. However, it also appears from figure 8 that the Freundlich model still can be considered valid and can be used to describe our adsorption of interest since the value of the non-linearity constant, $\mathrm{n}$, is 1.16 and hence greater than one indicating a favorable adsorption process according to the Freundlich model as shown in table 6.

Table 6. Langmuir and Freundlich isotherm constants for the adsorption of trypan blue dye using avocado seed powder.

\begin{tabular}{c|c|c|c}
\multicolumn{4}{c}{ Langmuir Adsorption Isotherm } \\
\hline $\mathbf{Q}_{\mathbf{m}}$ & $\mathrm{K}_{\mathrm{a}}$ & $\mathrm{R}^{2}$ & $\mathrm{R}_{\mathrm{L}}$ \\
\hline $\mathbf{1 9 . 3}$ & 0.12 & $\mathbf{0 . 9 9 4 8}$ & 0.464 \\
\hline \multicolumn{3}{c}{ Freundlich Adsorption Isotherm } \\
\hline $\mathbf{K}_{\mathbf{f}}$ & $\mathrm{n}$ & \multicolumn{2}{|c}{$\mathrm{R}^{2}$} \\
\hline $\mathbf{2 . 0 3}$ & 1.16 & $\mathbf{0 . 9 8 7 6}$
\end{tabular}

\subsection{Adsorption kinetics.}

The calculations were carried out for the $57.648 \mathrm{mg} / \mathrm{l}$ dye solution to investigate the kinetic model for this adsorption model. Other conditions like oscillation speed, temperature, and biosorbent dose were kept constant. Table 7 shows the results obtained from figures 9 and 10. It can be seen that the correlation coefficient $\left(\mathrm{R}^{2}=0.9916\right)$ for the pseudo-second-order kinetic model was higher than that of the pseudo-first-order kinetic model $\left(\mathrm{R}^{2}=0.8398\right)$.

Table 7. Results and calculations for the first-order model.

\begin{tabular}{c|c|c|c} 
Time (min) & $\mathbf{q}_{\mathbf{t}}$ & $\mathbf{q}_{\mathbf{e}}$ & $\log \mathbf{q}_{\mathbf{e}}-\mathbf{q}_{\mathbf{t}}$ \\
\hline $\mathbf{0}$ & 0 & 3.734 & 0.573 \\
\hline $\mathbf{1 0}$ & 3.09 & 3.74 & -0.191 \\
\hline $\mathbf{2 0}$ & 3.23 & 3.74 & -0.296
\end{tabular}




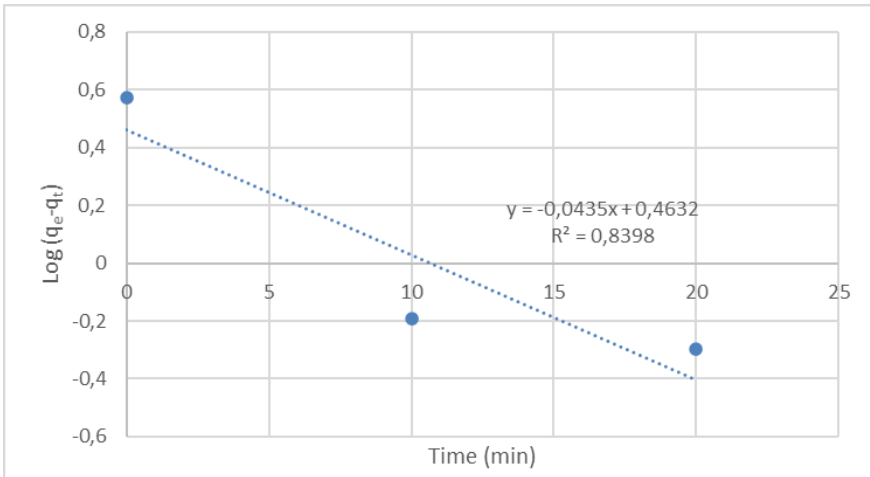

Figure 9. Pseudo-first order plot.

Furthermore, the experimental qe value of 3.74 was closer to the $\mathrm{q}_{\mathrm{e}}$ calculated from the pseudo-second-order kinetic plot $\left(\mathrm{q}_{\mathrm{e}}=4.12\right)$ instead of the one calculated from the pseudo-firstorder kinetic plot $\left(\mathrm{q}_{\mathrm{e}}=2.91\right)$ as shown in table 8 .

Table 8. Results and calculations for the second order model.

\begin{tabular}{c|c|c|c} 
Time (min) & qe & qt & t/qt \\
\hline $\mathbf{0}$ & 3.74 & 0 & $\infty$ \\
\hline $\mathbf{1 0}$ & 3.74 & 3.09 & 3.23 \\
\hline $\mathbf{2 0}$ & 3.74 & 3.23 & 6.18 \\
\hline $\mathbf{3 0}$ & 3.74 & 3.74 & 8.02 \\
\hline $\mathbf{4 0}$ & 3.74 & 3.86 & 10.3
\end{tabular}

The data extracted from the plots shown in table 9 indicate that the trypan blue dye's adsorption from aqueous solution perfectly follows the pseudo-second-order kinetic model. Since the data support that the mechanism is typically a pseudo-second-order adsorption mechanism, the trypan blue sorption process's overall rate appears to be controlled by chemical processes as opposed to physical ones.

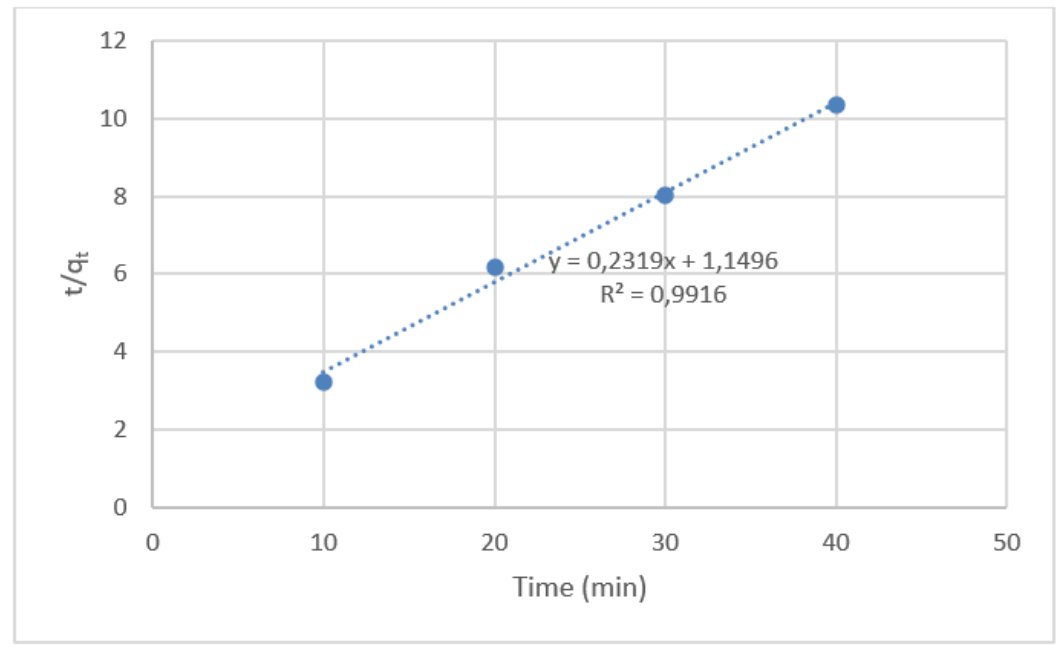

Figure 10. Pseudo-second order plot.

Table 9. Pseudo first and second order 'Models' parameters for the adsorption of trypan blue by avocado seed powder.

Pseudo-First Order Kinetic Parameters

\begin{tabular}{c|c|c|c|c}
\hline \multicolumn{7}{c}{ Pseudo-First Order Kinetic Parameters } \\
\hline Concentration $(\mathbf{m g} / \mathbf{L})$ & $\mathbf{q}_{\mathrm{e}}$ experimental & $\mathbf{q}_{\mathrm{e}}$ calculated & $\mathbf{K}_{\mathbf{f}}$ & $\mathbf{R}^{\mathbf{2}}$ \\
\hline $\mathbf{5 7 . 6 4 8}$ & 3.74 & 2.91 & 0.1 & $\mathbf{0 . 8 3 9}$ \\
\hline \multicolumn{5}{c}{ Pseudo-Second Order Kinetic Parameters } \\
\hline Concentration $(\mathbf{m g} / \mathbf{L})$ & $\mathbf{q e}$ experimental & qe calculated & $\mathbf{K}_{\mathbf{s}}$ & $\mathbf{R}^{\mathbf{2}}$ \\
\hline $\mathbf{5 7 . 6 4 8}$ & 3.74 & 4.312 & 0.047 & $\mathbf{0 . 9 9 1}$
\end{tabular}




\section{Conclusions}

This study demonstrated that avocado seed powder is an ideal and optimum biosorbent that can be used to remove trypan blue dye from polluted wastewater. The experimental results revealed that biosorption depends mainly on the contact time, initial dye concentration, and adsorbent dosage. However, it also might have been dependent on other variables like temperature and $\mathrm{pH}$. The latter two variables weren't included in this study since ties didn't permit, but for future work studying their effects on the adsorption efficiency of the adsorbent would prove very insightful.

The isotherm data plotted indicate that the Langmuir isotherm model fitted the trypan blue dye's removal from aqueous solution better with a correlation coefficient of 0.9948 as opposed to 0.9876 , the one obtained from plotting the Freundlich isotherm. Additionally, RL's separation factor was lying between zero and one at a value of 0.464 , indicating a favorable adsorption process according to the Langmuir model. Since the Langmuir isotherm model fitted the data better, therefore, the system exhibits monolayer biosorption on a homogenous surface.

The detailed kinetic studies confirmed that the sorption rate is a pseudo-second-order model with a higher correlation coefficient of 0.9916. The qe calculated from the pseudosecond-order kinetic plot $\left(\mathrm{q}_{\mathrm{e}}=4.12\right)$ was closer to the experimental $\mathrm{q}_{\mathrm{e}}$ value of $3.74 \mathrm{~g} / \mathrm{mg}$ than the calculated $\mathrm{q}_{\mathrm{e}}$ value from the pseudo-first-order kinetic model plot.

Additionally, since the pseudo-second-order adsorption mechanism was predominant, the trypan blue sorption process's overall rate appears to be controlled by chemical processes as opposed to physical ones.

\section{Funding}

The American University funded this research in Cairo (AUC).

\section{Acknowledgments}

The authors express their deep gratitude for the financial support of this research project that has been provided by The American University in Cairo (AUC).

\section{Conflicts of Interest}

The authors declare no conflict of interest.

\section{References}

1. Chen, S.T. Synthesis of $\mathrm{Pd} / \mathrm{Fe} 3 \mathrm{O} 4$ Hybrid Nanocatalysts with Controllable Interface and Enhanced Catalytic Activities for CO Oxidation. Journal of Physical Chemistry C 2012, 116, 12969-12976, https://doi.org/10.1021/jp3036204.

2. Radwan. N.R.E.; El-Shall, M.S.; Hassan, H.M.A. Synthesis and characterization of nanoparticle Co3O4, $\mathrm{CuO}$ and $\mathrm{NiO}$ catalysts prepared by physical and chemical methods to minimize air pollution. Applied Catalysis A: General 2007, 331, 8-18, https://doi.org/10.1016/j.apcata.2007.07.005.

3. Wang, H.L. Ni(OH)(2) Nanoplates Grown on Graphene as Advanced Electrochemical Pseudocapacitor Materials. Journal of the American Chemical Society 2010, 132, 7472-7477, https://doi.org/10.1021/ja102267j.

4. Wang, W.W.; Zhu, Y.J.; Ruan, M.L. Microwave-assisted synthesis and magnetic property of magnetite and hematite nanoparticles. Journal of Nanoparticle Research 2007, 9, 419-426, https://doi.org/10.1007/s11051005-9051-8.

5. Elazab, H. Microwave-assisted synthesis of $\mathrm{Pd}$ nanoparticles supported on $\mathrm{FeO}, \mathrm{CoO}$, and $\mathrm{Ni}(\mathrm{OH})$ nanoplates and catalysis application for CO oxidation. Journal of Nanoparticle Research 2014, 16, 1-11, https://doi.org/10.1177/0263617418771777. 
6. Mostafa, A.R.; Omar, H.A.S.; Hany, A.E. Preparation of Hydrogel Based on Acryl Amide and Investigation of Different Factors Affecting Rate and Amount of Absorbed Water. Agricultural Sciences 2017, 8, https://doi.org/10.4236/as.2017.82011.

7. Andrade, A.L. Catalytic Effect of Magnetic Nanoparticles Over the H(2)O(2) Decomposition Reaction. Journal of Nanoscience and Nanotechnology 2009, 9, 3695-3699, https://doi.org/10.1166/jnn.2009.ns53.

8. Kustov, A.L. CO methanation over supported bimetallic Ni-Fe catalysts: From computational studies towards catalyst optimization. Applied Catalysis a-General 2007, 320, 98-104, https://doi.org/10.1016/j.apcata.2006.12.017.

9. Lohitharn, N.; Goodwin, J.G. Impact of $\mathrm{Cr}, \mathrm{Mn}$ and $\mathrm{Zr}$ addition on Fe Fischer-Tropsch synthesis catalysis: Investigation at the active site level using SSITKA. Journal of Catalysis 2008, 257, 142-151, https://doi.org/10.1016/j.jcat.2008.04.015.

10. Moreau, F.; Bond, G.C. CO oxidation activity of gold catalysts supported on various oxides and their improvement by inclusion of an iron component. Catalysis Today 2006, 114, 362-368, https://doi.org/10.1016/j.cattod.2006.02.074.

11. Sarkari, M. Fischer-Tropsch synthesis: Development of kinetic expression for a sol-gel Fe-Ni/Al2O3 catalyst. Fuel Processing Technology 2012, 97, 130-139, https://doi.org/10.1016/j.fuproc.2012.01.008.

12. Elazab, H. The Effect of Graphene on Catalytic Performance of Palladium Nanoparticles Decorated with $\mathrm{FeO}, \mathrm{CoO}$, and $\mathrm{Ni}(\mathrm{OH})$ : Potential Efficient Catalysts Used for Suzuki Cross-Coupling. Catalysis Letters 2017, 147, 1510-1522, https://doi.org/10.1007/s10562-017-1990-Z.

13. Elazab, H.A. The continuous synthesis of Pd supported on Fe3O4 nanoparticles: A highly effective and magnetic catalyst for CO oxidation. Green Processing and Synthesis 2017, 6, 413-424, https://doi.org/10.1515/gps-2016-0168.

14. Elazab, H.A.; Sadek, M.A.; El-Idreesy, T.T. Microwave-assisted synthesis of palladium nanoparticles supported on copper oxide in aqueous medium as an efficient catalyst for Suzuki cross-coupling reaction. Adsorption Science \& Technology 2018, https://doi.org/10.1177/0263617418771777.

15. Elazab, H.A. Highly efficient and magnetically recyclable graphene-supported $\mathrm{Pd} / \mathrm{Fe} 3 \mathrm{O} 4$ nanoparticle catalysts for Suzuki and Heck cross-coupling reactions. Applied Catalysis A: General 2015, 491, 58-69, https://doi.org/10.1016/j.apcata.2014.11.033.

16. Hirvi, J.T.; Kinnunen, T.J.; Suvanto, M.; Pakkanen, T.A.; Norskov, J.K. CO oxidation on PdO surfaces. Journal of Chemical Physics 2010, 133, https://doi.org/10.1063/1.3464481.

17. Iglesias-Juez, A. Nanoparticulate Pd Supported Catalysts: Size-Dependent Formation of $\operatorname{Pd}(\mathrm{I}) / \operatorname{Pd}(0)$ and Their Role in CO Elimination. Journal of the American Chemical Society 2011, 133, 4484-4489, https://doi.org/10.1021/ja110320y.

18. Ivanova, A.S. Metal-support interactions in $\mathrm{Pt} / \mathrm{A} 12 \mathrm{O} 3$ and $\mathrm{Pd} / \mathrm{Al} 2 \mathrm{O} 3$ catalysts for $\mathrm{CO}$ oxidation. Applied Catalysis B-Environmental 2010, 97, 57-71, https://doi.org/10.1016/j.apcatb.2010.03.024.

19. Chattopadhyay, K.; Dey, R.; Ranu, B.C. Shape-dependent catalytic activity of copper oxide-supported $\operatorname{Pd}(0)$ nanoparticles for Suzuki and cyanation reactions. Tetrahedron Letters: International Organ for the Rapid Publication of Preliminary Communications in Organic Chemistry 2009, 50, 3164-3167, https://doi.org/10.1016/j.tetlet.2009.01.027.

20. Hoseini, S.J. Modification of palladium-copper thin film by reduced graphene oxide or platinum as catalyst for Suzuki-Miyaura reactions. Applied Organometallic Chemistry 2017, 31.

21. Hosseini-Sarvari, M.; Razmi, Z. Palladium Supported on Zinc Oxide Nanoparticles as Efficient Heterogeneous Catalyst for Suzuki Miyaura and Hiyama Reactions under Normal Laboratory Conditions. Helvetica Chimica Acta 2015, 98, 805-818.

22. Nasrollahzadeh, M.; Ehsani, A.; Jaleh, B. Preparation of carbon supported CuPd nanoparticles as novel heterogeneous catalysts for the reduction of nitroarenes and the phosphine-free Suzuki Miyaura coupling reaction. New Journal of Chemistry 2015, 39, 1148-1153, https://doi.org/10.1039/C4NJ01788A.

23. Nasrollahzadeh, M. Palladium nanoparticles supported on copper oxide as an efficient and recyclable catalyst for carbon(sp2) carbon(sp2) cross-coupling reaction. Materials Research Bulletin 2013, 68, 150154, https://doi.org/10.1016/j.materresbull.2015.03.051.

24. Mandali, P.K.; Chand, D.K. Palladium nanoparticles catalyzed Suzuki cross-coupling reactions in ambient conditions. Catalysis Communications 2016, 31, 16-20, https://doi.org/10.1016/j.catcom.2012.10.020.

25. Wang, Y. CuO Nanorods-Decorated Reduced Graphene Oxide Nanocatalysts for Catalytic Oxidation of CO. Catalysts 2016, 6, https://doi.org/10.3390/catal6120214.

26. Igarashi, H.; Uchida, H.; Watanabe, M. Mordenite-supported noble metal catalysts for selective oxidation of carbon monoxide in a reformed gas. Chemistry Letters 2000, 11, 1262-1263, https://doi.org/10.1246/cl.2000.1262.

27. Liu, W.H.; Fleming, S.; Lairson, B.M. Reduced intergranular magnetic coupling in Pd/Co multilayers. Journal of Applied Physics 1996, 79, 3651-3655, https://doi.org/10.1063/1.361193.

28. Luo, J.Y. Mesoporous $\mathrm{Co}(3) \mathrm{O}(4)-\mathrm{CeO}(2)$ and $\mathrm{Pd} / \mathrm{Co}(3) \mathrm{O}(4)-\mathrm{CeO}(2)$ catalysts: Synthesis, characterization and mechanistic study of their catalytic properties for low-temperature CO oxidation. Journal of Catalysis 2008, 254, 310-324, https://doi.org/10.1016/j.jcat.2008.01.007. 
29. Pavlova, S.N. The influence of support on the low-temperature activity of Pd in the reaction of CO oxidation on Kinetics and mechanism of the reaction. Journal of Catalysis 1996, 161, 517-523, https://doi.org/10.1006/jcat.1996.0213.

30. Diyarbakir, S.M.; Can, H.; Metin, O. Reduced Graphene Oxide-Supported CuPd Alloy Nanoparticles as Efficient Catalysts for the Sonogashira Cross-Coupling Reactions. Acs Applied Materials \& Interfaces 2015, 7, 3199-3206, https://doi.org/10.1021/am507764u.

31. Feng, Y.S.; Ma, J.J.; Kang, Y.M.; Xu, H.J. ChemInform Abstract: PdCu Nanoparticles Supported on Graphene: An Efficient and Recyclable Catalyst for Reduction of Nitroarenes. ChemInform 2015, 70, 61006105, https://doi.org/10.1016/j.tet.2014.04.034.

32. Feng. Y.S.; Ma, J.J.; Kang, Y.M.; Xu, H.J. PdCu nanoparticles supported on graphene: an efficient and recyclable catalyst for reduction of nitroarenes. Tetrahedron 2014, 70, 6100-6105, https://doi.org/10.1016/j.tet.2014.04.034.

33. Liu, Y.; Ma, H.; Wu, J.D.W.; Ren, X.; Yan, T.; Pang, X.; Wei, Q. Ultrasensitive electrochemical immunosensor for SCCA detection based on ternary $\mathrm{Pt} / \mathrm{PdCu}$ nanocube anchored on three-dimensional graphene framework for signal amplification. Biosensors \& Bioelectronics 2016, 79, 71-78, https://doi.org/10.1016/j.bios.2015.12.013.

34. Shafaei, D.A.; Saravani, H.; Noroozifar, M. Novel fabrication of PdCu nanostructures decorated on graphene as excellent electrocatalyst toward ethanol oxidation. International Journal of Hydrogen Energy 2017, 42, 15149-15159, https://doi.org/10.1016/j.ijhydene.2017.04.280.

35. Elazab, H.A. Investigation of Microwave-assisted Synthesis of Palladium Nanoparticles Supported on $\mathrm{Fe}_{3} \mathrm{O}_{4}$ as an Efficient Recyclable Magnetic Catalysts for Suzuki Cross - Coupling. The Canadian Journal of Chemical Engineering 2018, 96, 250-261, https://doi.org/10.1002/cjce.23402.

36. Radwan, M.A.; Omar Al-Sweasy, Sadek, M.A.; Elazab, H.A. Investigating the Agricultural Applications of Acryl Amide based Hydrogel. International Journal of Engineering and Technology(UAE) 2018, 7, 168171.

37. Zakaria, F.; Radwan, M.A.; Sadek, M.; Elazab, H.A. Insulating material based on shredded used tires and inexpensive polymers for different roofs. International Journal of Engineering and Technology(UAE) 2018, 7, 1983-1988, https://doi.org/10.14419/ijet.v7i4.14081.

38. Nasser, R.; Radwan, M.A.; Sadek, M.A.; Elazab, H.A. Preparation of insulating material based on rice straw and inexpensive polymers for different roofs. International Journal of Engineering and Technology(UAE) 2018, 7, 1989-1994, https://doi.org/10.14419/ijet.v7i4.14082.

39. Ghobashy, M.; Gadallah, M.; El-Idreesy, T.T.; Sadek, M.A.; Elazab, H.A. Kinetic Study of Hydrolysis of Ethyl Acetate using Caustic Soda. International Journal of Engineering and Technology(UAE) 2018, 7, 1995-1999, https://doi.org/10.14419/ijet.v7i4.14083.

40. Samir, N.S.; Radwan, M.A.; Sadek, M.A.; Elazab, H.A. Preparation and Characterization of Bullet-Proof Vests Based on Polyamide Fibers. International Journal of Engineering and Technology(UAE) 2018, 7, 1290-1294.

41. Ashraf, B.; Radwan, M.A.; Sadek, M.A.; Elazab, H.A. Preparation and Characterization of Decorative and Heat Insulating Floor Tiles for Buildings Roofs. International Journal of Engineering and Technology (UAE) 2018, 7, 1295-1298, https://doi.org/10.14419/ijet.v7i3.13177.

42. Mandali, P.K.; Chand, D.K. Palladium nanoparticles catalyzed Suzuki cross-coupling reactions in ambient conditions. Catalysis Communications 2016, 31, 16-20, https://doi.org/10.1016/j.catcom.2012.10.020.

43. Elazab, H. Investigation of Microwave-assisted Synthesis of Palladium Nanoparticles Supported on Fe3O4 as an Efficient Recyclable Magnetic Catalysts for Suzuki Cross - Coupling. The Canadian Journal of Chemical Engineering 2019, 97, 920-928, https://doi.org/10.1002/cjce.23402.

44. Radwan, M.A.; Rashad, M.A.; Sadek, M.A.; Elazab, H.A. Synthesis, Characterization and Selected Application of Chitosan Coated Magnetic Iron Oxide Nanoparticles. Journal of Chemical Technology and Metallurgy 2019, 54, 303-310.

45. Abdelhady, H.H.; Elazab, H.A.; Ewais, E.M.; Saber, M.; El-Deab, M.S. Efficient Catalytic Production of Biodiesel Using Nano-Sized Sugarbeet Agro-Industrial waste. Fuel 2019, 261, https://doi.org/10.1016/j.fuel.2019.116481.

46. Elazab, H.A. Investigation of Microwave-assisted Synthesis of Palladium Nanoparticles Supported on $\mathrm{Fe}_{3} \mathrm{O}_{4}$ as an Efficient Recyclable Magnetic Catalysts for Suzuki Cross - Coupling. The Canadian Journal of Chemical Engineering 2019, 97, 1545-1551, https://doi.org/10.1002/cjce.23402.

47. Elazab, H.A.; Sadek, M.A.; El-Idreesy, T.T. Facile Synthesis of Reduced Graphene Oxide-Supported $\mathrm{Pd} / \mathrm{CuO}$ Nanoparticles as an Efficient Catalyst for Cross-Coupling Reactions. Journal of Chemical Technology and Metallurgy 2019, 54, 934-946.

48. Elazab, H.A.; El-Idreesy, T.T. Polyvinylpyrrolidone - Reduced Graphene Oxide - Pd Nanoparticles as an Efficient Nanocomposite for Catalysis Applications in Cross-Coupling Reactions. Bulletin of Chemical Reaction Engineering and Catalysis 2019, 14, 490-501, https://doi.org/10.9767/bcrec.14.3.3461.490-501.

49. Elazab, H.A.; Ali, R.; Siamaki, B.; Gupton, F.; El-Shall, M.S. Pd-Fe $\mathrm{O}_{4} / \mathrm{RGO}$ : a Highly Active and Magnetically Recyclable Catalyst for Suzuki Cross Coupling Reaction using a Microfluidic Flow Reactor. 
Bulletin of Chemical Reaction Engineering and Catalysis 2019, 14, 478-489, https://doi.org/10.9767/bcrec.14.3.3518.478-489.

50. Elazab, H.A.; Radwan, M.A.; El-Idreesy, T.T. Facile microwave-assisted synthetic approach to palladium nanoparticles supported on copper oxide as an efficient catalyst for Heck cross-coupling reactions. International Journal of Nanoscience 2019, 18, https://doi.org/10.1142/S0219581X18500321.

51. Elazab, H.A.; Hassan, S.A.; Radwan, M.A.; Sadek, M.A. Microwave-assisted Synthesis of Graphene supported Hexagonal Magnetite for Applications in Catalysis. International Journal of Innovative Technology and Exploring Engineering 2019, 8, 5511-5513.

52. Elazab, H.A.; Radwan, M.A.; Sadek, M.A. Hydrothermal Synthesis of Palladium nanoparticles supported on $\mathrm{Fe}_{3} \mathrm{O}_{4}$ Nanoparticles: an Efficient Magnetic Catalysts for CO Oxidation. Biointerface Research in Applied Chemistry 2019, 9, 3906-3911, https://doi.org/10.33263/BRIAC92.906911.

53. Aboul-Fotouh, T.M.; Sherif, K.; Ibrahim, M.A.; Sadek, M.A.; Elazab, H.A. High Octane Number GasolineEther Blend. International Journal of Innovative Technology and Exploring Engineering 2019, 8, 732-739, https://doi.org/10.35940/ijitee.F3610.078919.

54. Elazab, H.; El-Idreesy, T. Optimization of the catalytic performance of $\mathrm{Pd} / \mathrm{Fe} 3 \mathrm{O} 4$ nanoparticles prepared via microwave-assisted synthesis for pharmaceutical and catalysis applications. Biointerface Research in Applied Chemistry 2019, 9, 3794-3799, https://doi.org/10.33263/BRIAC91.794799. 